ASPECTS OF EMPTY CATEGORIES IN XHOSA WITHIN THE THEORY

OF GOVERNMENT AND BINDING

Marianna W. Visser

The main purpose of this paper is to explore various agreement phenomena in Xhosa within the government-binding (GB) framework of generative grammar. The principles of the null subject parameter postulated in (Chomsky 1981), which accounts for the absence of an overt subject in phonetic representation, are shown to extend to the analysis of agreement phenomena in Xhosa which are characteristic of Bantu languages in general. In the proposed analyses the empty pronominal nonanaphor (pro) plays a crucial role. In particular it is argued that, apart from occurring as subject and object, pro can appear as the head of an NP, and as the complement of prepositions, the possessive morpheme $\underline{a}$, and the copulative.

In section 1, the typology of empty categories is briefly reviewed. In sections 2 and 3 , respectively, subject and object verb agreement in Xhosa are dealt with. It is argued that the subjectival concord (SC) and the objectival concord or clitic (OC) are nominal morphemes irrespective of whether they cooccur with an NP subject and object respectively. The proposed account therefore opposes the view that the SC and $O C$ in Bantu languages are pronouns (i.e. NP categories) wherever these concords do not cooccur with an NP subject and object respectively. In section 3, the reflexive clitic in Xhosa is examined. Although the reflexive clitic, being characteristically invariable, is not an agreement concord, it is in complementary distribution with the object clitic. This gives rise to the question whether a reflexive verb must be analysed in the same way as its counterpart with a nonreflexive (=object) clitic. In section 4, agreement between nominal modifiers and the head $N$ is examined. Agreement in prepositional phrases, possessive constructions and copulative constructions is discussed in section 5 . 
Phonologically null elements in syntax, generally referred to as empty categories (ECs), have been the subject of considerable discussion in recent literature within the GB framework -- see (Chomsky 1981, 1982), (Aoun 1982), (Rizzi 1982) and many others. Four types of ECs are distinguished in (Chomsky 1982):

$\begin{aligned} &\left.\begin{array}{rl}\text { (i) } & \text { NP-trace } \\ \text { (ii) } & \text { variable }\end{array}\right\}=\text { "trace" } \\ & \text { (iii) } \text { PRo } \\ & \text { (iv) } \text { pro }\end{aligned}$

Note that a distinction is made between NP-trace and the trace of a whword, a variable. The EC trace is generated by the rule Move $\propto$. Trace is coindexed with its antecedent by Move $\propto$, by convention. The pronominal anaphor PRO is the base-generated subject of infinitival clauses that is coindexed with its antecedent by the rule of control, one of the rules of construal in the LF (read "logical form") component which relates antecedents and anaphors. If PRO is not coindexed it is arbitrary in reference. The pronominal nonanaphor pro is the basegenerated subject of sentences lacking an overt subject in nuli subject languages. pro may contain the grammatical features person, number, gender and, possibly, Case. The category pro is furthermore proposed as the NP associated (coindexed) with the clitic in languages that allow the cliticisation option. In the subsequent discussion, pro is of major concern.

The binding theory, as represented in (2), defines the relations of anaphors and pronominals to their antecedents (if any) in terms of structural configurations:

(2) Binding theory

(a) an anaphor is bound in its governing category;

(b) a pronominal is free in its governing category. ${ }^{1)}$ 
The binding theory in (2) makes no mention of $R$ (eferential)-expressions (i.e. names and variables). Therefore R-expressions are free. ${ }^{2)}$ Four types of categories are identified by principles (a) and (b) of the binding theory (2), as shown in (3). Chomsky (1982:78) refers to the paradigm (3) to show that the typology of ECs as determined by the binding theory simply mirrors that of overt categories with lexical content.

$\frac{\text { Type of nominal cate- }}{\text { gory }}$

(i) [+ anaphor, - pronomina1]

(ii) $[-\underset{\text { anaphor }}{\text { minal }}]$
(iii) $\left[\begin{array}{r}\text { anaphor } \\ \text { minal }]\end{array}\right]+$ prono-
(iv) $\left[-\begin{array}{r}\text { anaphor } \\ \text { minal }\end{array}\right]$
Overt category

reciprocals (each other) reflexives (himself, etc.)

pronouns ( $I$, he, etc.)

lexical NPs
Empty category

NP-trace

pro

PRO

variable

The fact that the EC PRO does not have an overt counterpart of the type ( 3 iii) is explained as follows. The crucial property of PRO, namely that it is ungoverned, follows from the binding theory. If PRO had a governing category, it would be subject to both principles (2) (a) and (b) --- PRO being a pronominal anaphor --- which is impossible. Thus PRO does not have a governing category, thereby satisfying principles (a) and (b) of the binding theory (2) vacuously. Since all NPs with phonetic content must have Case by the Case filter proposed in (Chomsky 1981:49), and Case-assignment is contingent on government, no overt category of the type (3iii) is permissible, because it would lack Case.

A category of type ( $3 i i$ ) is called a pure pronominal, in contrast with PRO, the pronominal anaphor (3iii). Chomsky (1982:83) points out that a pure pronominal always serves as an R-expression, having either independent reference, or the reference of a linguistic antecedent. The possible relation of a pure pronominal to an antecedent is determined by semantic rules applying to LE representations in the sence of (Chomsky 1975: 105) : 


\begin{abstract}
"The logical forms so generated (i.e., generated by the formal grammar -- M.W.V.) are subject to further interpretation by other semantic rules ... interacting with other cognitive structures, giving fuller representations of meaning."
\end{abstract}

The LF representation assigned to a linguistic expression is considered to reflect all the semantic properties of the expression that are determined by sentence grammar. The LF component includes rules of coreference identifying antecedent-anaphor relations, rules of control through which PRO, the subject of an infinitival clause, is coindexed with its antecedent (if any), rules of quantifier interpretation, etc. Properties of the semantic interpretation of linguistic expressions that are not determined at LF are considered to be grammar-external --- see (Chomsky 1981:4). The $L F$ representation of an expression serves as input to rules determining extra-gramatical semantic properties such as presupposition, discourse properties, reference in discourse context, and properties depending on knowledge of the world which form part of a "fuller" interpretation of the expression concerned.

It might be appropriate at this stage to reflect briefly on the argument by which the reference of the subjectival concord (SC) in Bantu is used as evidence for the syntactic status of the SC. On this argument the SC is considered to be a pronoun (i.e. a nominal category) in sentences in which it does not cooccur with an overt NP subject (as in (6) below). The occurrence of sentences without overt noun subjects in Bantu, is typically regarded as a discourse-bound phenomenon: the reference of the SC is determined by the context of discourse. The SC is thus accorded the status of a pronoun (a nominal category) on the strength of the fact that it has the reference of some other NP within the context of discourse. It is clear from the discussion above that this argument does not hold if the crucial property of the SC, viz. its discourse-determined reference, is taken to be an extra-grammatical semantic property.

The null subject parameter

The nuil subject parameter relates to the option languages have of allowing sentences without an overt subject. According to Chomsky (1981:241), this option is associated with sufficiently rich inflection, where "sufficiently rich inflection" is generally taken to refer to overt subject- 


\section{Visser, 119}

vetb agreement morphology. Agreement entails identity of the grammatical features person, number, gender and, perhaps, Case. Languages which accept the option of allowing sentences without an overt subject are called null subject (or pro-drop) languages; languages that reject this option are called non-null subject (or non-pro-drop) languages. The EC pro is generated as NP subject in sentences without an overt subject in null subject languages. As is the case with all ECs, the content of pro must be determined by some other element of the structure in which it appears. According to Chomsky (1982:85) AGR (reement), the complex of grammatical features in INFL(ection) ${ }^{3)}$ locally determines the content of the null subject pro in null subject. languages, where the notion "local determination" can be understood as government by AGR. Local determination of the content of the subject, or goverment by AGR, is thus a requirement for the EC pro to appear as subject. AGR in INFL is coindexed (by cosuperscripting) with the NP subject it governs, thus sharing its gramatical features under strict feature-matching.

Chomsky (1982:86) proposes that the notion "sufficiently rich" inflection with which the null subject parameter is associated, could be characterised in terms of Case theory. It is assumed that, apart from the features person, number and gender, AGR also contains Case in the null subject languages. Thus the empty subject pro is assigned Case through coindexing with AGR. Since AGR in non-null subject languages cannot contain Case as feature, pro in subject position would not receive Case through coindexing with AGR and would therefore be "invisible" to the rules of LF responsible for assigning it the appropriate $\theta$-role. ${ }^{4)}$ The null subject parameter then reduces to the question of whether or not AGR contains Case at D-structure. 5)

\subsection{Subject-verb agreement in Xhos a}

In the Bantu languages, subject-verb agreement is phonetically realised as a verbal prefix, in contrast with Italian-type languages where it is rea!ised as a verbal suffix. In the Xhosa sentences in (4), subject-verb agreement, as real ised by the subjectival concord (SC), is underlined. The abbreviation PT is used to indicate the present tense morpheme. As is characteristic of Bantu, Xhosa nouns belong to gerider classes. 
Visser, $\quad 120$

(4) (a) abafundi ba-bhaz-a wiwo

students they-write-FT examination

"the students are writing examination"

(b) amapolisa $\underline{a}$-bamb-a isela

police they-arrest-PT thief

"the police are arresting the thief"

(c) indoda izungis-a uphahla

man he-fix-PT roof

"the man is fixing the roof"

Henceforth reference to features of inflection other than those relevant to subject-verb agreement will be omitted for expository purposes. In the D-structures (5) of the sentences in (4) AGR is coindexed with the NP subject it governs, sharing its grammatical features:
(a) abafundi ${ }^{i} \operatorname{AGR}^{i}[\mathrm{VP}[\mathrm{V}$ bhal $][\mathrm{NP}$ uviwo $]]$
(b) amapolisa ${ }^{i} \operatorname{AGR}^{i}\left[{ }_{V P}\left[V^{b a m b}\right]\left[\right.\right.$ NP $\left.\left.^{\text {isela }}\right]\right]$
(c) indoda ${ }^{i} \quad \operatorname{AGR}^{i}\left[\mathrm{VP}_{\mathrm{V}}[\right.$ lungis $\left.]\left[\mathrm{NP}^{\text {uphahla }}\right]\right]$

In Xhosa, which displays the rich inflectional system characteristic of Bantu, an overt noun subject may be absent. AGR governs (hence locally determines the feature content of) the NP subject, therefore pro may be generated in this position. In (6), the sentences of (4) appear without their respective overt subjects. The underlined morpheme in each case represents the SC. The approximate D-structures of the examples in (6) are given in (7). The grammatical feature of the EC pro will henceforth be specified in brackets just below it. Thus, pro indicates that pro [C.2]

contains the grammatical gender feature of class 2 .

$$
\begin{aligned}
& \text { (a) } \frac{b a-b h a z-a}{\text { they-write-PT examination }} \\
& \text { "they are writing the examination" }
\end{aligned}
$$


(b) $\quad a-b a m b-a \quad i s e z a$

they-arrest-PT thief

"they are arresting the thief"

(c) $\quad \underline{i}$-Zungisa uphahla

he-fix-PT roof

"he is fixing the roof"

(7) (a) $\left.\operatorname{pro}^{\mathrm{i}} \mathrm{C} .2\right] \mathrm{AGR}^{\mathrm{i}}\left[\mathrm{VP}_{\mathrm{V}}{ }_{\mathrm{bhal}}\right] \quad[\mathrm{NP}$ uviwo $]$

(b) $\underset{\mathrm{Cro}}{\mathrm{i}} \mathrm{C} .6] \mathrm{AGR}^{\mathrm{i}}\left[\mathrm{VP}[\mathrm{V}\right.$ bamb $]\left[\mathrm{NP}^{\text {isela }}\right]$

(c) pro $\left.^{\mathrm{i}} \mathrm{C} .9\right] \mathrm{AGR}^{\mathrm{i}} \mathrm{I}_{\mathrm{VP}}[\mathrm{V}$ lungis $] \quad[\mathrm{NP}$ uphahla $]$

The first and second person NP subjects are always base-generated as pro with the relevant features for person and number, as in the sentences in (8) whose D-structures are exhibited in (9):

$$
\begin{aligned}
& \text { (a) ndi-biz-a abantwana } \\
& \text { I-call-PT children } \\
& \text { "I am calling the children" } \\
& \text { (b) ni-qath-a abantu } \\
& \text { you(pl)-cheat-PT people } \\
& \text { "you(pl) are cheating the people" }
\end{aligned}
$$

(9) (a) $\underset{[1 \text { sing }]}{\operatorname{pro}} \operatorname{AGR}^{i}\left[{ }_{V P}\left[\mathrm{~V}^{\text {biz }}\right] \quad\left[\mathrm{NP}^{\text {abantwana }}\right]\right.$

(b) $\underset{\left[2 \mathrm{pl}^{\mathrm{i}}\right]}{\operatorname{Fr}} \mathrm{AGR}^{\mathrm{i}}\left[\mathrm{VP}_{\mathrm{V}}[\mathrm{qath}] \cdot\left[\mathrm{NP}^{\mathrm{abant} u}\right]\right.$

In some Bantu languages, for example Swahili, the subject-verb agreement norpheme associated with animate subject NPs is always that of class 1 (singular) or class 2 (plural), irrespective of the noun class to which 
Visser, 122

the animate subject belongs. Class 1 and class 2 almost exclusive1y contain animate nouns. In these languages, therefore, the feature [animate], in addition to the features person, number and gender, must be assumed to be specified in AGR in the case of sentences vith animate subject NPs' in order to account for the class $1 / 2$ morphology of subject-verb agreement. In the case of animate subjects in noun classes other than classes 1 and 2, the feature [animate] in AGR is taken to be the dominant feature with respect to deternining subject-verb agreement. Modifier agreement in these languages, interestingly, does not reflect the above-mentioned distinction conceming animacy: a modifier exhibits the morphology of the (implied) modified NP. ${ }^{6}$ )

\section{$4 \quad$ Cliticisation}

4.1 The pair clitic-pro

Chomsky (1981:275f; 1982:87f) extends the line of thinking which led to the postulation of the EC pro as the subject in null subject languages, to the process of cliticisation. Languages may have the base form (10) or (11):

(10) NP INFL $\left[\mathrm{VP}^{c l-V ~ N P}\right]$

(11) NP INFL $[$ VP $\vee$ NP $]$

(10) represents the base structure of languages which accept the option of permitting clitics. This property of D-structure may derive from the lexicon or the categorial component according to Chomsky (1981:275). The cliticisation option is independent of the null subject parameter (i.e., the option of allowing the EC pro to be base-generated as subject). French, for instance, differs from Italian in that it is not a null subject language, but $i t$ is similar to Italian in that it permits clitics. cliticisation exhibits great variation cross-linguistically, and different languages may have different properties concerning, for example, the ordering and movement of clitics. The clitic cl is a nominal morpheme, not an NP category. The clitic, like AGR in INFL, is a complex of the 
Visser, 123

Gramatical features person, number, gender. Languages which allow cliticisation behave idiosyncratically with respect to the (non-) occurrence of the postverbal lexical NP whose gramatical features the clitic cl exhibits.

Chomsky (1981:275) points out the symmetry between agreement in the null subject languages and the process of cliticisation. The relation of AGR to the overt NP subject or empty subject pro, seems quite similar to the relation between the clitic and the NP object in structures of the form (10). Chomsky proposes that the EC pro is generated as NP object in structures where the clitic does not cooccur with an overt postverbal NP object whose features it contains. Object pro is coindexed with the clitic $c i$ by cosuperscripting. Hence there is identity of gramatical features between the clitic cl and pro, as in (12):

(12) NP INFI $\left[\mathrm{vP} c l^{\mathrm{i}}-\mathrm{v}\right.$ pro $\left.{ }^{\mathrm{i}}\right]$

The generation of pro as NP object coindexed with the clitic is permitted by the same principle as that which permits the occurrence of an empty subject in sentences with sufficiently rich inflection.

The notion "local determination" discussed in $\S 3$ above is also as sumed with respect to cliticisation. Recall that AGR in INFL locally detertines, i.e. governs, the NP subject, allowing the EC pro to be generated as subject. In the same way, the clitic cl locally deternines the NP object, allowing pro to be base-generated as object. Since the clitic is an arreement marker of the NP object, it seems possible to modify the notion "local determination (government) by AGR" in such a way that it will generalize to both subject and object pro.

\subsection{Case-assignment to pro}

Chonsky (1981:334) as sumes the principle (13) for Case-assignment and the Case filter (14):

(:3) The chain $C=\left(c_{1}, \ldots, \alpha_{n}\right)$ has the Case $k$ if and only if for some $i, x_{i}$ occupies a position assigned $k$ by $E$. 
Every lexical NP is an element of a chain with Case. ${ }^{7)}$

In several studies on clitic constructions it is proposed that the clitic cl "absorbs" Case --- cf. (Jaeggli 1982, chapter 1) and (Aoun 1981, chapter 4) for evidence from Italian and Spanish. Consequently the overt NP object whose features the clitic contains may not appear in direct postverbal position, since it is not assigned Case by the verb. The (doubled) NP object may appear only if it is preceded by an element by which it can be assigned Case. On this principle, known as Kayne's generalisation, an NP object may be doubled by a clitic only if the former is preceded by a preposition --- see (Aoun 1981:275).

Aoun (1981:330ff). further suggests that the clitic cl may also "manifest" (bear) Case. It is important to note the difference between Case absorption and Case manifestation. Generally, a verb assigns objective Case to the NP it governs. In certain instances, however, a verb which governs an NP does not asign Case to this NP since the Case marking properties of the verb are absorbed. Passive morphology, for example, absorbs Case -- cf. (Chomsky 1981:124). The passive verb does not assign Case to the NP it governs. Consequently the NP object has to move to a position where it can receive Case in order to satisfy the Case filter (14) which requires that every lexical NP must be an element of a chain with Case.

Aoun (1981:329) argues that the clitic is a nominal element which, as such, needs Case. It thus absorbs the Case-feature of the governor, i.e. the verb. Whereas passive morphology absorbs Case but does not manifest (bear) Case, the clitic, as a nominal element, absorbs and can manifest the Case feature. If the clitic does manifest Case, then the chain (cr, pro) will have Case; if the clitic does not manifest Case, the chain will be ( $c l$, lexical NP) and the doubled NP must be Case-marked by some other element in accordance with Kayne's generalisation. Chomsky (1982:88) notes that some stipulation presumably would have to be made to al low a chain headed by a clitic, since it is normally required that a chain must be headed by an element in an A-position. ${ }^{8}$ ).

Aoun (op. cit.: 336-338) notes, however, that the process of clitic doubling in Modern Greek displays strikingly different properties from those attributed to clitic doubling above. In Greek, clitics do not 
absorb Case: a Case-marker need not be inserted before the doubled lexical NP. Aoun accounts for this fact by proposing that clitics in Greek are not independent nominal elements (as clitics in French and Spanish are) but object agreement markers which do not absorb Case. Hence the lexical NP object associated with the clitic is assigned object Case by its governor, the verb. Aoun (op. cit.: 337) proposes, therefore, that there are two means by which a clitic can receive Case. A clitic can receive Case either (i) directly from its governor (as in Italian and Spanish), or (ii) through the doubled element with which it agrees (as in Modern Greek). Aoun points out that the two possibilities do not overlap. The first applies when the clitic is a nominal element, in which case it absorbs the Case feature assigned by the governor. The second applies when the clitic is not an independent nominal element, but an agreement marker which acquires its features (person, number, gender and Case) from the element with which it agrees.

\subsection{Cliticisation in Xhosa}

In terms of Aoun's characterisation of clitic constructions given above, the clitic in Xhosa (and in Bantu generally) must be classed with the clitic. in Modern Greek, rather than with the clitic in French, Spanish and Italian. Object-verb agreement being one of a wide range of agreement phenomena in Bantu, it is generally accepted in Bantu linguistics that the clitic is an agreement marker.

Cliticisation in Xhosa, as typically in Bantu languages, is manifested by the appearance of the clitic or objectival concord (OC) directly before the verb. Xhosa verb morphology allows only one clitic to precede the host (i.e. the verb to which the clitic is attached). An overt (doubled) NP object associated with the clitic may appear in postverbal position, or the clitic may occur without an associated overt NP object. In the latter instance, pro is base-generated as the NP object. Consider the sentences in (15) where the doubled NP appears in immediate postverbal position as it does in the sentences of (4). In (16), the clitic appears without an associated (doubled) lexical NP object. The D-structures of the sentences in (16) are roughly as in (17). The clitic in each sentence is underlined: 
(a) abafunci ba-ya-lu-bhal-a uviwo students they-PT-it-write-PT examination

"the students are writing the examination"

(b) amapolisa a-ya-ti-bamb-a isela police they-PT-him-arrest-PT thief

"the police are arresting the thief"

(c) indoda i-ya-lu-lungis-a uphahla

man he-PT-it-fix-PT roof

"the man is fixing the roof"

(16) (a) abafundi ba-ya-zu-bhal-a

students they-PT-it-write-PT

"the students are writing it"

(b) amapolisa $a-y a-\underline{-i}-b a m b-a$

police they-PT-him-arrest-PT

"the police are arresting him"

(c) indoda i-ya-lu-Zungis-a

man he-PT-it-fix-PT

"the man is fixing it"

(17) (a) $\left[\mathrm{NP}^{\text {abafundi }}\right]$ AGR $\left[\mathrm{VP} c Z^{i}\left[\mathrm{~V}^{\text {bhal }}\right]\right.$ pro $\left.{ }^{i}\right]$

(b) [ $\mathrm{NP}_{\text {amapolisa }]} \mathrm{AGR} \cdot\left[\mathrm{VP} \mathrm{e}^{i}\left[\mathrm{v}^{\mathrm{bamb}}\right]\right.$ pro $\left.{ }^{i}\right]$

(c) $[\mathrm{NP}$ indoda $] \quad A G R \cdot\left[\mathrm{VP} e \tau^{i}\left[\mathrm{~V}^{\text {lungis }}\right]\right.$ pro $\left.^{\mathrm{i}}\right]$

Where both the clitic and the overt NP object appear in a sentence, as in (15), the NP object receives greater emphasis than in a sentence where it appears without the clitic, as in (4) above. 


\section{t.3.1 Case-assignment to pro}

There is no evidence from Xhosa to support the adoption of a device of Case absorption by the clitic. In Xhosa, the doubled NP may occur immediately postverbally, as in (15) above, as it does in the corresponding sentence without the clitic, as in (4). Doubled NP constructions in Xhosa therefore do not provide support for Kayne's generalisation. Consider again the examples (4a), (15a), (16a) and the D-structure (17a), repeated here:

(4) (a) abafundi ba-binal-a uviwo students they-write-PT examination

"the students are writing the examination"

(15) (a) abafundi ba-ya-lu-bhal-a uviwo students they-PT-it-write-PT examination "the students are writing the examination"

(16) (a) abafundi ba-ya-lu-bhal-a students they-PT-it-write-PT "the students are writing it"

(a) [NP abafundi $]$ AGR $\left[\mathrm{VP} c l^{i}[\mathrm{~V}\right.$ bhal $]$ pro $\left.{ }^{i}\right]$

In (15a), the doubled NP is assigned (objective) Case by the verb bhal ("write") in exactly the same way as in (4a), hence the chain (cl, lexical $\mathrm{NP}$ ) has Case. Since the clitic in Xhosa, and in Bantu generally, is an agreement marker, and not an independent nominal element (as in French, Italian and Spanish) it does not absorb the Case feature of the governor, the verb. Rather, the postverbal NP, whether it is lexical as in (15a), or empty (i.e. pro) as in (16a), is assigned objective Case by its governor, the verb, in exactly the same way as the NP object in the corresponding sentence without the clitic would be assigned Case by the transitive verb. 
The fact that the reflexive clitic (henceforth, r-clitic) and the oc or object clitic (henceforth also non-r(eflexive) clitic) in Bantu are related, has often been observed. The exact nature of this relatedness, however, has not yet been captured satisfactorily. ${ }^{9)}$ The r-clitic in Xhosa, for example, is similar to the non-r-clitic in that both are generated in the same slot and occur in the immediate preverbal position in verbal morphology. Furthermore, the r-clitic and the non-r-clitic have the same tone. ${ }^{10)}$ Hence, the r-clitic and the non-r-clitic are in complementary distribution. The r-clitic differs from the non-r-clitic in that the former is an ivariable morpheme, zi-, which cannot be considered to contain any of the grammatical features person, number, or gender as the non-r-clitic can. -zi- can appear with any antecedent, regardless of the latter's grammatical features, as illustrated in (18). The r-clitics are underlined.

(a) umntwana $u-y a-z i-h l a m b-a$ $[\mathrm{c.1}]$

child he-PT-self-wash-PT

"the child washes himself"

(b) amadoda a-ya-zi-thand-a [c.6]

men they-PT-self-1ike-PT

"the men like themselves"

(c) intombi i-ya-zi-hombis-a [c.9] girl she-PT-self-beautify-PT

"the girl beautifies herself"

(d) umfundi u-ya-zi-theng-el-a imoto $[\mathrm{c} \cdot 1]$ student he-PT-self-buy-for-PT car

"the student is buying himself a car"

(e) umsebenzi u-va-zi-nik-a ixesha zokuphumla $[\mathrm{c} .1]$
labourer he-PT-self-give-PT time of-rest
"the labourer is giving himself a rest" 
In (18a-c), the reflexive -zi- appears with single-object verbs, i.e. verbs with the subcategorisation frame NP] . In $(18 d, e)$ - $\underline{i i-}$ appears with double-object verbs, i.e., verbs with the subcategorization frame [ NP NP]. The behavior of the r-clitic with respect to the verb's argument structure appears to be similar to that of the non-rclitic. A verb which has an r-clitic takes one NP object, hence one argument, less. If the r-clitic appears in the verbal morphology, a single-object verb may not take a postverbal NP object, as shown in (19a), while a double-object verb may take only one postverbal NP object, as shown in (19b). The r-clitic -zi- thus seems to satisfy an argument in the argument structure of the verb.

(a) *zomntwana u-ya-zi-hzamb-a ikomityi child he-PT-self-wash-PT cup (cf. (18a))

(b) tumfundi u-ya-zi-theng-el-a uyise imoto student he-PT-self-buy-for-PT father car (cf. (18d))

The r-clitic in Xhosa differs from the non-r-clitic in that no lexical NP object can cooccur with the former, as is the case with the latter. Xhosa therefore does not have overt anaphors. Van Eeden (1956:104) de-scribes the relationship between the r-clitic and the non-r-clitic (i.e. oc) in Xhosa as follows:

The reflexive formative -zi- is not a concord; it is also not self evidently a pronoun [clitic in this paper -M.W.V.J. It is a constant or invariable formative or infix, which retains the same form for all persons and classes, and in this respect thus differs radically from a concord [my translation --- M.W.V.]

Doke and Mofokeng (1957:244) have the following to say about the nature of the dissimilarity between the r-clitic and the non-r-clitic in Southern Sotho which, like Xhosa, is a Southern Bantu language. 
There is an invariable prefix, akin in use to the objectival concords, which is used immediately before transitive verb stems to give to the verbs reflexive force. In Southern

Sotho the reflexive prefix is $-\underline{i-}$, and unlike the objectival concords, it is invariable for all persons and classes, and is thus not concordial in its function [my emphasis - - M.W.V.]

The term "concord" in the above quotations, refers to agreement morphemes of various sorts, such as the SC (AGR in INFL) and the OC (non-r-clitic) which are specified for the grammatical features person, number and gender, and with which an NP subject and object, respectively, may cooccur.

If it is assumed that the r-clitic in Xhosa is similar to the non-r-clitic cooccurring with an empty NP object (i.e. pro), as in (16), then sentences containing an r-clitic should be analysed similarly to (16). Thus the structure of Xhosa reflexive constructions can be represented roughly as in (20):

$$
\left.\mathrm{NP} I \mathrm{NFL}\left[\mathrm{VP} \mathrm{r}-\mathrm{Cl}-\mathrm{V}_{\mathrm{NP}}^{\mathrm{i}}\right]^{\mathrm{i}}\right]
$$

An obvious question arising from this analysis concerns the nature of the postverbal EC associated with the r-clitic. This question may be formulated as follows: how does the empty NP object coindexed with the r-clitic fit into the typology of ECs shown in (3) above? To answer this question, two subsidiary questions must be considered, viz.

(i) what are the grammatical features exhibited by the r-clitic $-\underline{z i}-?$

(ii) which of the four possible types of EC defined in (3) can appear as the EC coindexed with the r-clitic and sharing its features?

As regards the first question -- (i) above -- it was shown in (18) that the r-clitic -zi- in Xhosa is an invariable morpheme which is used with all persons and all noun gender classes. The fact that it is morphologically similar to the pronominal (non-r-) clitics of class 8 and class 10 is irrelevant: these features cannct be specified for the r-clitic 
since it would yield semantically anomalous reflexive constructions. The r-clitic in Xhosa, unlike the reflexive in English -- himself, herself, etc. -- , therefore cannot be considered to contain any of the grammatical features person, number, or gender. It exhibits the single feature [+ reflexive $]$.

As regards question ( $i i)$, let us consider the ability of each of the ECs in (3) to appear in the postverbal NP-position coindexed with the r-clitic -zi- in turn. A first possibility, which can be dismissed out of hand, is that the EC associated with the r-clitic in (20) is an NP-trace, i.e. an EC of the type ( $3 i)$. Such an analysis would, crucially, have to assume that the r-clitic is generated postverbally and subsequently moved to the preverbal position, leaving a trace. However, there is no justification for the view that the r-clitic in Xhosa is not base-generated in the preverbal position in the same way as non-r-clitics. Since no movement takes flace in the derivation of Xhosa reflexive constructions, the postverbal $E C$ in (20) cannot be the trace of the r-clitic. A second possibility, viz. that the empty NP coindexed with the r-clitic in (20) is a variable, i.e. an EC of the type ( $3 i v$ ), is excluded for the same reason, as suming the characterisation of a variable as a "case-marked trace" - cf. (Chomsky 1981:69). A third possibility, the analysis of the postverbal EC in (20) as a pure pronominal, i.e. an EC of the type (3ii), is excluded by virtue of the incompatibility of the grammatical features exhibited by the r-clitic and the coindexed postverbal EC on the one hand and, on the other hand, the features associated with ECs of the type (3ii), such as pro. Suppose that the EC associated with the r-clitic in (20) is the EC pro. Then the r-clitic and the coindexed EC must share pronominal features. But the r-clitic, hence the coindexed EC, also contains the feature [+ reflexive] and would therefore be specified as [+ anaphor] for purposes of the typology of ECs in (3). This would be inconsistent with the [- anaphor] specification of ECs of the type (3ii). The postverbal EC in (20) therefore cannot be a pure pronominal, pro, of the type (3ii). Consider, fourthly, the possibility that the EC coindexed with the rclitic in (20) is [+ pronominal, + anaphor], i.e. like PRO, an EC of the type ( $3 i i i)$. This possibility is excluded by the binding theory (2) since an EC of the type ( $3 i i i)$ must be bound (by (2a)) as well as free (by (2b)) in its governing category, as is the case with PRo, the subject of infinitival clauses. The latter satisfies the binding theory vacuously 
by not having a governor, hence a governing category. AGR in INFL is the governor of the clausal subject, but since INFL in infinitival clauses does not contain AGR, the subject of an infinitive is not governed and, hence, does not have a governing category. An argument along these lines, however, is impossible in the case of the postverbal EC in (20). Since it is governed by the verb, it has a governing category, the marrix $S$, in which it is simultaneously required to be bound and free by the principles of the binding theory. The classification of the postverbal EC coindexed with the r-clitic in (20) as a pronominal anaphor similar to PRO is thus incompatible with the binding theory and therefore unacceptable.

Note that the postverbal EC in (20) can in fact be neither an EC of the type (3ii), like pro, nor an EC of the type (3iii), like PRO, for another reason. Both these types of EC are "pronominal". In section 2, it was maintained that a category is defined as "pronominal" if it contains any of the grammatical features person, number, or gender. As was shown in answer to question (i) above, none of these features is exhibited by the r-clitic -zi- and, hence, by the EC coindexed with it. The postverbal $E C$, coindexed with the rclitic in (20), is specified for the single feature [+reflexive]. Thus, the EC associated with the r-clitic in Xhosa must be regarded as an empty pure anaphor of type (3i), similar to NP-trace, but differing from NP-trace in that it is base-generated and not derived by the rule Move $\alpha$.

Although the analysis of Xhosa reflexive constructions proposed above is consistent with the principles of the GB theory, an alternative analysis, based on (Grimshaw 1980), ${ }^{11}$ ) merits careful consideration. Grimshaw proposes an analysis of French reflexivization crucialiy involving the transitivity valence of verbs. She argues convincingly, presenting evidence from French NP-inversion and causative constructions, that the r-clitic in French has the effect of intransitivizing the verb. The verb with the r-clitic does not take an NP with the grammatical function object, in contrast with its counterpart with a pronominal (i.e., non-r-) clitic which does take such an NP, hence is transitive.

An analysis of Xhosa reflexivization along the lines of (Grimshaw 1980) seems especially promising if the extremely limited syntactic distribution of the r-clitic-zi- in Xhosa is taken into account. Assuming that the structure $(20)$ is accepted for Xhosa reflexive constructions, it does 
strike one as peculiar that the empty NP containing the single feature $[+R$ (eflexive) $]$ in (20) is restricted to the NP-position associated with the object function. It may not appear in any other syntactic position in Xhosa. In this Xhosa differs from, for example, English in which the reflexive can occur in the prepositional object position (cf. he is talking about himself), or in the by-object position in a passive construction (cf. John was hurt by himself). On the analysis (20) only one interpretation of the Xhosa r-clitic is possible, viz. an interpretation consistent with the fact that it is associated with an element bearing the object function. This seems to be an unacceptable consequence.

Grimshaw's analysis, on the other hand, is compatible with Doke and Mofokeng's view of the reflexive clitic as a morpheme which "gives reflexive force to the verb". On this analysis the r-clitic-zi- in xhosa intransitivizes the verb, decreasing its transitivity valence by one. In other words, a verb with an r-clitic takes one argument less in its argument structure than its counterpart without the r-clitic. Hence a single-object verb becomes intransitive when it has an r-clitic (cf. $(18 a-c),(19 a)$ above) and a double-object verb becomes a single-object verb (cf. (18d,e), (19b) above). The reflexive affix -zi-containing the features [+ $R$ (eflexive), - transitive] is cliticised to the verb by a rule of derivational morphology. These features are assumed by the head $v$. The morphological structure of a Xhosa reflexive verb may then be represented roughly as in (21):

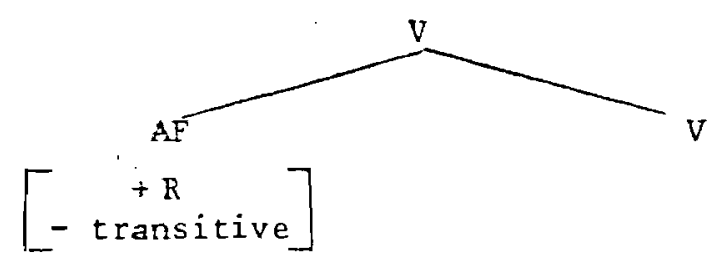

The acquisition of the feature [- transitive] by the head $V$ has the consequence that the number of object arguments in the argument structure of the non-reflexive counterpart of $\mathrm{V}$ is decreased by one. The impression that the r-clitic itself satisfies the object argument, is therefore false as mentioned above. The reflexive meaning is borne by the verb itself. Thus, the thematic role associated with the subject of a reflexive verb is something like "self-doer". Verbs like -bon-'see', thand'like', -hlamb- 'wash' will have the feature $[+R]$ in their lexical 
Visser, 134

entries, while verbs like -sel-'drink', -cing- 'think', which cannot undergo reflexivization, will lack this feature. Since such an analysis of Xhosa reflexivization does not involve binding relations between NPs in syntactic structure it is unproblematic with regard to the binding theory.

It must be pointed out, as noted by Vitale (1981:134-136), that the above analysis of the reflexive clitic does not extend to the possessive reflexive forms, e.g. ngokwabo, ngokwayo, etc., in Xhosa. These forms are not true reflexives in the sense that the verb itself bears the meaning of reflexivity as described above. Vitale argues that the presence of the possessive form merely has the function of adding the feature [+ emphatic]. to the NP with which it cooccurs. The presence of a possessive reflexive form therefore does not affect the argument structure of the verb in any way. Consider the sentences in (22). where the possessive reflexive forms are underlined:
(a)
umphathiswa $u-b i k-a$
imithe tho ngokwakhe
minister he-announce-PT laws
himself
"the minister announces the laws himself"
(b) indoda i-Zungis-a uphahla ngokwayo
"the man fixes the roof himself"
(c) ndi-sebenz-a ngokwam
I-work-PT myself
"I myself work"

The possessive reflexive differs from the reflexive -zi- in at least two respects. First, the possessive reflexive may be omitted without changing the meaning of the sentence, apart from causing the absence of the additional emphasis. The omission of the reflexive -zi-from a sentence, however, drastically changes the meaning of the sentence and may even cause the sentence to be ungrammatical. Compare, for example, the effect that the omission of the reflexive -zi- has in the case of the sentences (18a, d), repeated here. 
(18)

(a)

umbtwana w-ia-zi-hzamb-a

child he-PT-refl.-wash-PT

"the child is washing himself"

reflexive omitted

umntwana $u-y a-h z a m b-a$

child he-PT-wash-PT

"the child is washing" (something else)

(d) romfundi u-ya-zitheng-el-a imoto

student he-PT-ref1.-buy-for-PT car

"the student buys a car for himself"

reflexive omitted

*umfundi $u$-theng-el-a imoto

student he-buy-for-PT car

"the student buys for the car"

The second difference between the possessive reflexive and the reflexive -zi- is that the former has no effect on the transitivity of the verb, whereas the reflexive -zi-does, as explained above.

\section{$6 \quad$ Implications}

The central concern of the above discussion was the role of the EC pro in Xhosa syntax, specifically in the analysis of subject-verb agreement and cliticization or object-verb agreement. It has appeared from the discussion that the EC pro is associated with overt agreement: where there is overt agreement between the subject and verb (the SC in Xhosa) or between the object and verb (the clitic or OC in Xhosa) an overt subject and object respectively need not appear.

Given the fact that the Bantu languages exhibit such a wide range of agreement phenomena the obvious question that arises is whether other instances of the occurrence of pro may not be found in Xhosa syntax. Two additional types of agreement phenomena in Xhosa will be discussed 
very briefly. The first is the agreement between a noun and its modifiers. The second concerns the agreement exhibited by (i) prepositional constructions with associative na- ('and, with'), instrumental nga('by means of, about'), and locative ku- ('at, to'), (ii) the possessive construction, and (iii) the copulative construction.

Apart from subject-and object-verb agreement, modifier agreement is characteristic of Bantu. In an NP, all modifiers of the head agree with the latter in the gramatical features person, number and gender. Consider the sentences (23), where the agreement morphemes are underlined.
(a) [NP lo mntwana wenkosi omhle] u-ya-dzal-a this child of chief-pretty he-PT-play-PT "this pretty child of the chief is playing"
(b) $\quad[\mathrm{NP}$ aba bantwana benkosi abahle] ba-ya-dzall-a these children of-chief pretty they-PT-play-PT "these pretty children of the chief are playing"

The use of modifiers without a head noun is very common in Bantu. Corresponding to the sentences of $(23 a, b)$ we find $(24 a, b)$ in which the NP lacks a head.
(a) [NP zo wenkosi omhle] u-ya-dial-a
this of-chief pretty he-PT-play-PT
"this pretty (one) of the chief is playing"
(b) $\quad[\mathrm{NP}$ aba benkosi $\underline{a b a h z e}]$ ba-ya-dzal-a these of-chief pretty they-PT-play-PT
"these pretty ones of the chief are playing"

Each of the modifiers in (24) may also appear on its own as sentence subject. The phenomenon of modifiers appearing without their head noun appears to be similar in principle to the null subject parameter ( $\S_{3}$ above) and to cliticisation (\$4). It seems reasonable, then, to propose that in languages where the modifiers of a noun exhibit overt agreement with the head noun, the head noun position may be empty, containing only 
the grammatical features person, number and gender which are overtly realised on its modifiers. In these languages, then, a lexical head need not appear in the head position of an NP. A percolation device may be assumed by which the gramatical features of the EC pro percolate to the modifiers of the head, in the same way as when the head is lexical. ${ }^{12}$ ) The postulation of pro as the head of an NP has the advantage of allowing modifier agreement in an NP to be analysed in a unitary way, whether an overt head is present or not.

The EC pro may be base-generated as the head of an NP in the same way as it may be base-generated as the NP subject (see \$3) and the NP object (see \$4) of a sentence. Overt agreement is a crucial requirement in all three instances. Although it is the case that in Xhosa (and in Bantu generally) the three possible occurrences of pro, namely as subject (under the null subject parameter), as object (under the cliticization option) and as head of NP are all attested, this need not be the case. The occurrence of one of these instances. of pro in a language does not necessitate the occurrence of any of the others.

The second type of agreement mentioned above as a possible instance of the occurrence of pro in Xhosa syntax is agreement (i) in prepositional constructions, ( $i i)$ in the possessive construction, and ( $i i i$ ) in the copulative construction. The nominal element (concord) which may appear in these constructions corresponds to the absolute pronoun without its final syllable -na. Consider the sentences (25)-(27), where the nominal elements under discussion are underlined. Note that in these examples there is no intonational break between the italicized nominal element and the following noun. If there is a pause, the following noun is not considered part of the clausal structure.

\section{Prepositions}

(i) a,sociative na-

(a) utitshala u-theth-a na-bo abafundi teacher (s)he-speak-PT with-them students "the teacher is speaking with the students"

(b) indoda i-neokol-a na-zo iindwendwe man he-chat-PT with-them guests "the man is chatting with the guests" 
(ii) instrumental nga-

(a) utitshala $u$-theth-a nga-bo abafundi teacher (s)he-speak-PT about-them students "the teacher is speaking about the students"

(b) indoda $i$-ncokol-a nga-zo iindwendwe man he-chat-PT about-them guests "the man is chatting about the guests"

(iii) locative. ku-

(a) utitshala $u$-theth-a ku-bo abafundi teacher (s)he-speak-PT at-them students "the teacher is speaking at the students"

(b) indoda i-ncokol-a ku-zo iindwendwe man he-chat-PT at-them guests "the man is chatting at the guests"

\section{Possessive}

(a) utitshala u-makish-a iincwadi za-bo abafundi teacher (s)he-mark-PT books of-them students

"the teacher is marking the students" books"

(b) indoda i-phak-a ukutya kwa-zo iindwendwe man he-dish up-PT food of-them guests

"the man is dishing up the food of the guests"

(27) Copula

(a) nga-bo- abafundi

it-is-they students

"it is the students"

(b) $2 i-z 0$ iindwencwe

it-is-they guests

"it is the guests" 
In the above examples, the underlined nominal element, or concord, may be oritted, and the preposition, possessive, or copula may be directly prefixed to the noun, as shown in the sentences $(28)-(30)$.

\section{Prepositions}

(i) associative na-

utitshaza u-theth-a nabafundi (na + abafundi)

teacher (s)he-speak-PT with-students

"the teacher is speaking with the students"

(ii) instrumental nga-

utitshala u-theth-a ngabafundi (nga + abafundi)

teacher (s)he-speak-PT about-students

"the teacher is speaking about the students"

(iii) locative $\underline{k u}-$

utitshala u-theth-a kubafundi (ku+abafundi)

teacher he-speak-PT at-students

"the teacher is speaking at the students"

(29)

\section{Possessive}

Utitshala u-makish-a iincwadi zabafundi ( $z a+a b a f u n d i)$

teacher (s)he-mark-PT books of-students

"the teacher is marking the students' books"

(30) Copula

$$
\begin{aligned}
& \text { ngabafundi (ng + abafundi) } \\
& \text { it-is-students } \\
& \text { "it is the students" }
\end{aligned}
$$

In each of the sentences (25)-(27) the NP which follows the underlined concord that agrees with the NP may be omitted, as in the examples (31)-(33): 
(i)

.....associative na-

utitshala $u$-theth-a na-bo

teacher (s)he-speak-PT with-them

"the teacher is speaking with them"

(ii) instrumental ngá-

utitshala u-theth-a nga-bo

teacher (s)he-speak-PT about-them

"the teacher is speaking about them"

(iii) locative ku-

utitshala u-theth-a ku-bo

teacher (s)he-speak-PT at-them

"the teacher is speaking at them"

\section{(32) Possessive}

utitshala u-makish-a iincwadi za-bo

teacher (s)he-mark-PT books of-them

"the teacher is marking their books"

(33) Copula

$$
\begin{aligned}
& \text { nga-bo } \\
& \text { it-is-they } \\
& \text { "it is them" }
\end{aligned}
$$

Recall that the central principle which operated in the case of the null subject phenomenon and cliticisation was that if there is overt agreement (appropriately specified AGR in INFL, or a clitic), the overt subject or object may be absent and the EC pro is base-generated as the subject or object in the corresponding D-structure. It seems upon closer inspection of the examples (25)-(33) as if the same principle applied in these constructions. If there is overt agreement (or concord) on a preposition, 
Visser, 141

the possessive, or the copula, as in (25)-(27), the NP with which the concord agrees may be missing, as in (31)-(33). Thus the D-structures of these sentences are assumed to contain pro. On this analysis the D-structures of the sentences (31)-(33) are (34)-(36) respectively, where agr represents an agreement marker.

\section{Prepositions}

(i)

$$
\begin{aligned}
& \text { associative na- }
\end{aligned}
$$

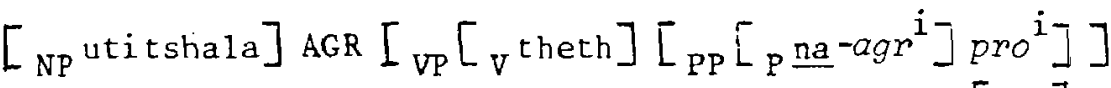

$$
\begin{aligned}
& \text { [c.2] }
\end{aligned}
$$

(ii) instrumental nga-

$$
\begin{aligned}
& {\left[{ }_{N P} \text { utitshala }\right] \operatorname{AGR}\left[{ }_{\mathrm{VP}}\left[\mathrm{V}^{\text {theth }}\right]\left[\mathrm{PP}_{\mathrm{P}}\left[\mathrm{nga}-a g r^{\mathrm{i}}\right] \text { pro }^{\mathrm{i}}\right]\right]} \\
& {[\mathrm{c} .2]}
\end{aligned}
$$

(iii) locative $\underline{k u-}$

$$
\begin{aligned}
& {\left[\mathrm{NP} \text { utitshala] AGR }\left[\mathrm{VP}[\mathrm{V} \text { theth }]\left[\mathrm{PP}_{\mathrm{P}}\left[\underline{k u}^{\mathrm{kg}} \mathrm{r}^{\mathrm{i}}\right] \mathrm{pro}^{\mathrm{i}}\right]\right]\right.} \\
& \text { [c.2] }
\end{aligned}
$$

\section{Possessive}

$\left[{ }_{N P} u t i t s h a l a\right] \operatorname{AGR}\left[{ }_{V P}\left[V^{\text {makish }}\right]\left[_{N P}\right.\right.$ incwadi POSS-agr ${ }^{i}$ pro $\left.\left.^{i}\right]\right]$.

(36)

$$
\begin{aligned}
& \text { Copula } \\
& {[\mathrm{NP}]\left[\mathrm{VP}{ }^{\mathrm{COP}-\alpha g \mathrm{r}^{\mathrm{i}}} \mathrm{pro}^{\mathrm{i}}\right]} \\
& {[c .2]}
\end{aligned}
$$

If these observations about noun-modifier agreement and agreement on prepositions, the possessive and copula are correct, then it is clear that the relationship between the EC pro and overt agreement is still largely unexplored. The Bantu languages, as highly inflected languages, exhibit a wide range of agreement phenomena which merit careful examination before final conclusions can be drawn. The approach suggested above for the ana- 
lysis of subject- and object-verb agreement, modifier-noun agreement and agreement on prepositions, the possessive and the copula in Xhosa is attractive because, on the one hand, it offers the possibility of a unitary treatment of agreement phenomena and, on the other hand, it is striking in its overall simplicity. 


\section{Visser, 143}

NOTES

1. The notion "bound" can be understood as coindexing of a category with a c-comanding element. The formal definition of the notions "bound" and "free" given in (Chomsky 1981:184) is assumed:

(i) $\alpha$ is $x$-bound by $\beta$ if and only if $\alpha$ and $\beta$ are coindexed, $\beta$ c-commands $\alpha$ and $\beta$ is in an $x$-position

(ii) $\propto$ is $X$-free if and only if it is not $X$-bound

(iii) $\alpha$ is locally bound by $\beta$ if and only if $\alpha$ is $x$-bound by $\beta$ and if $y$ Y-binds $\alpha$ then either $\gamma Y$-binds $\beta$ or $Y=\beta$

(iv) $\alpha$ is locally $x$-bound by $\beta$ if and only if $\alpha$ is locally bound and $\mathrm{x}$-bound by $\beta$.

In (i) and (ii), "bound" and "free" are defined by replacing "X" with "A" or "A" respectively. (A-positions include positions such as subject and object; $\bar{A}$-positions include the comp position and the position of an adjunct.) In (iii), "X" and " $Y$ " may be independently replaced by "A" or "A". The theory of binding is a theory of A-binding.

As for the notion "governing category", the definition of Chomsky $(1981: 188)$ is assumed:

(v) $\alpha$ is the governing category for $\beta$ if and only if $\alpha$ is the minimal category containing $\beta$ and a governor of $f$, where $\propto$ is NP or $S$.

"Government" in the core cases may be informally defined as follows:

(vi) a lexical category governs the elements it is subcategorised for for equivalently, in terms of $x$-bar theory, a category governs its complements in the construction of which it is the head);

(vii) the AGR (reement) element in INFL governs the subject. 
2. In (Chomsky 1981:188, 1982:20) the binding theory includes a third principle which states: an R-expression is free.

According to Chomsky $(1982: 31)$ (i) can be understood as follows:

(ii) An R-expression must be A-free in the domain of the operator that $\bar{A}$-binds it.

Chomsky (op.cit.: 35-6) shows that (ii) is in effect built into the definition of the notion "variable". Excluding the trace in COMP of an operator from the class of binders, a variable is defined as a category that is locally operator-bound (i.e. $\bar{A}$-bound). Principle (i) can therefore be entirely eliminated. Cf. also n. 8 below.

3. Chomsky (1981:52) assumes the following expansion for $S$

(i) $\mathrm{S} \longrightarrow \mathrm{NP}$ INFL VP

He assumes "that INFL may in principle be the collection of features $[[ \pm$ Tense $],(A G R)] "$. In (Chomsky 1982:86) he states that "the AGR element is a set of specifications for the features person, gender, number, and (in pro-drop languages) Case".

4. Cf. Chomsky 1981:40-41, 176-177 for a discussion of the relevant principles of $\theta$-theory.

5. Tuller (1982) proposes that AGR can become Case-marked by two different methods: (i) it can contain Case as an inherent feature (just as it can contain the pronominal features person, number and gender), or (ii) it can become Case-marked as the result of movement of a case-bearing element to its (= AGR) position. Method (i) is postulated for languages such as Italian with complete AGR with all (lexical and null) subject NPs, method (ii) for languages such as Standard Arabic and Breton where incomplete and null AGR, respectively, occur with lexical NPs, and complete AGR only with null subjects. Tuller notes that languages which exemplify the relationship lexical subjcct with incomplete/nul1 AGR and null subject with complete AGR are also 
those which have no pronoun subjects. Diachronic pronoun subject movement to INFL is postulated to explain why complete AGR appears only with null subjects and why pronoun subjects are absent. Tuller furthermore points out that Hausa agreement seems to display properties characteristic of both methods of Case-marking. The verbal morphology in Hausa exhibits complete AGR with all (lexical and empty) subject NPs and it does not have subject pronouns. To explai, this, Tuller proposes (on the basis of evidence from Proto-Hausa) that (diachronic) pronoun subject movement to INFL first took place and that AGR subsequently assumed the Case feature inherently.

Subject agreement in Xhosa is similar to that of Hausa. Xhosa, as all Bantu languages, has complete AGR with all subjects, i.e., with lexical as well as empty subjects. Thus it seems reasonable to account for Xhosa subject-verb agreement in terms of Case-marking of AGR as well. On this analysis, then, (diachronic) pronoun subject movement to INFL first took place, AGR thus receiving all the pronominal features. Subsequently AGR as sumed Case as an inherent feature. Cf. Givón 1976 for a discussion of the pronominal origin of the subject agreement marker in the Bantu 1 anguages.

Tuller suggests, furthernore, that the absence of subject pronouns in some languages can be attributed either to there being no phonologically overt counterpart to subject pro in the lexicon of to subject pro never being assigned a phonological matrix by a "spel1out" rule.

6. As the purpose of this paper is to present the outline of an approach to the analysis of agreement phenomena in Xhosa (and Bantu in general several aspects which merit thorough investigation are not discussed, e.g. the specification of agreement features in conjoined NFs --cF. Roberts \& Wolontis 1974 --- and in constructions such as passiv where movement has applied.

7. Cf. Chomsky 1981:45 for an explanation of the notion "chain".

8. Cf. Chomsky 1981:331. The positions in which the grammatical func- 
Visser, $\quad 146$

tions associated with the head of a construction (subject-of-S and complements of $\bar{X} \quad(X=N, V, A, P))$ are assigned, are referred to as A-positions. Non-A ( $\bar{A}-)$ positions are the COMP position and the position of adjunct (as in subject-inversion constructions) --- cf. Chomsky 1981:45.

9. Cf. Vitale 1981:134-144 for an analysis of reflexivization in Swahili.

10. Cf. Van Eeden 1956:105.

11. Cf. Marantz 1981:178-196 for an analysis of lexical reflexivization in several languages.

12. According to Chomsky (1981:49f) "Case is assigned to NPs by virtue of the configurations in wich they appear and percolates to their heads". 
Visser, 147

\section{REFERENCES}

Aoun, J.

1981 The formal nature of anaphoric relations, Ph.D. dissertation, MIT.

Borer, H.

1981 Parametric variation in clitic constructions, Ph.D. dissertation, MIT.

Bokamba, E.C.

1980 "Verbal agreement as! a non-cyclic rule in Bantu". Papers from the sixteenth regional meeting of the Chicago Linguistic Society, University of Chicago.

Chomsky, N.

1975 Reflections on Language. London: Temple Smith.

1980 'A note on non-control PRO'. Journal of Linguistic Research, vol. 4 , no. 1 .

1981 Lectures on Covernment and Binding. Dordrecht: Foris.

1982 Some concepts and consequences of the theory of Government and Binding. Cambridge, Massachusetts: MIT Press.

Davis, L.

1982 'Argument-binding and control'. Journal of Linguistic Research, vol. 2 , no. 1 .

Doke, C.M. \& S.M. Mo fokeng.

1957 Textbook of Southern Sotho Grammar: Cape Town: Longman.

Duranti, A.

1979 'Object clitic pronouns in Bantu and the Topicality Hierarchy'. Studies in African Linguistics, vol. 10, no. 1.

Evans, G.

1980 'Prenouns'. Linguistic Inquiry, vol. 11, no. 2. 
Gary, J.O. \& E.L. Keenan

1977 'On collapsing grammatical relations in Universal Grammar'. In: P. Cole \& J.M. Saddock (eds.), Syntax and Semantics 8. New York: Academic Press.

Givón, T.

1970 'The magical number two, Bantu pronouns and the theory of pronominalization'. Studies in African Linguistics, vol. 1, no. 3 .

1976 'Topic, pronoun and grammatical agreement'. In: C. Li (ed.), Subject and Topic.

Gregerson, E.A.

1967 Prefix and pronoun in Bantu. (Supplement of International Journal of American Linguistics 33, (Part 2)).

Grimshaw, $J$.

1981

'On the Iexical representation of Romance reflexive clitics'. In: Bresnan J. (ed.) The Mental representation of grammatical relations. Cambridge: MIT Press.

Guma, S.M.

An outline structure of Southern Sotho. Pietermaritzburg: Shuter and Shooter.

Hyman, L.M. \& A. Duranti

1982 'On the object relation in Bantu'. In: P.J. Hopper \& S.A. Thompson (eds.), Syntax and Semantics 15. New York: Academic Press.

Hyman, L.M. \& M. Morolong

1977 'Animacy, Objects and clitics in Sesotho'. Studies in African Linguistics, vol. 8 , no. 3 .

Jaeggli, 0 .

1982 Topics in Romance Syntax. Dordrecht: Foris. 
Kunene, E.

1975 'Zulu pronouns and the structure of discourse'. Studies in African Línguistics, vol. 6, no. 2 .

Landsberg, J.C.

1979 Kongruensie in Zulu, M.A. thesis, University of Potchefstroom.

Marantz, A.

On.the nature of grammatical relations, Ph.D. dissertaticn, MIT.

Quirk, R. (et al)

1972 A grammar of contemporary English. London and New York: Longman.

Rizzi, L.

1982 Issues in Italian Syntax: Dordrecht: Foris.

Roberts, L. \&. Wolontis

1974 'Conjunction and concord in Bantu'. In: Voeltz, E. (ed.) Third Annual Conference of African Linguistics, Indiana University Publications, African series, vol. 7.

Suner, M.

1982 'On null subjects'. Linguistic Analysis, vo1. 9, no. 1. Tuller, L.

1982 'Null subjects and objects in Hausa'. Journal of Linguistic Research, vo1. 2 , no. 2 .

Van Eeden, B.I.C.

1956 Zoeloe-grammatika. Stellenbosch: University Publishers and Booksellers.

Vitale, A.J.

1981 Swahili syntax. Dordrecht: Foris. 
Stellenbosch Papers in Linguistics, Vol. 12, 1984, 115-150 doi: 10.5774/12-0-103

Visser, 150

Ha id, $B$.

1979 'The development of the Swahili object marker: a study of the interaction of syntax and discourse'. In: T. Givón (ed.), Syntax and Semantics 12. New York: Academic Press.

Zwicky, A.

1977

On clitics. Distributed by Indiana University Linguistics Club, Bloomington, Indiana.

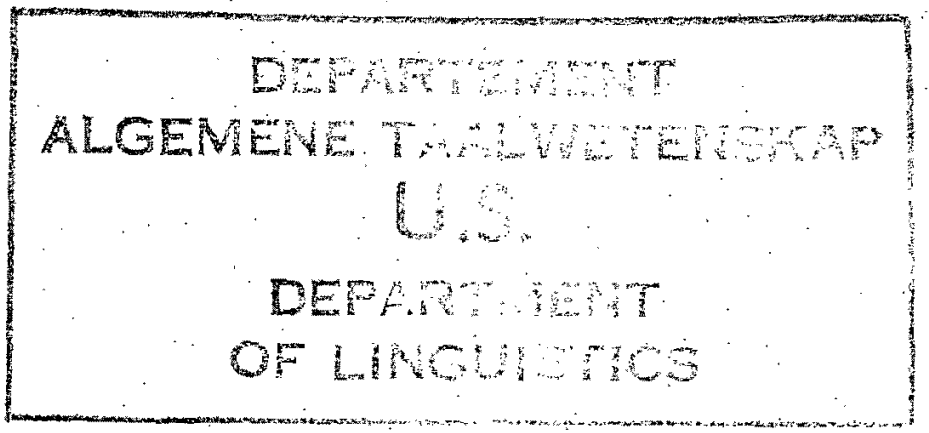

